\title{
Procesos de recepción y apropiación de discursos mediáticos en asentamientos precarios: Estudio de caso (Nueva Asunción, Hyndaya)
}

\author{
Perla Dayana MASsó SOLER \\ Universidad de Oriente (Cuba) \\ perla_masso@fch.uo.edu.cu
}

Recibido: 11 de abril de 2013

Aceptado: 23 de septiembre de 2013

\begin{abstract}
Resumen
La presente investigación se inscribe en la perspectiva teórica de las representaciones sociales. Desde una línea de reflexión empírica parte del mundo de vida cotidiana de los sujetos sociales de un sector sociológico específico y sus interacciones en la construcción de sentidos, indagando en los niveles objetivables y aspectos discursivos de los universos simbólicos constituidos en torno a los medios de comunicación masiva y sus relatos/discursos en la modelación de la realidad. En el análisis de las estructuras representacionales, como pensamiento socialmente construido, en el asentamiento precario Nueva Asunción (Hyndaya) se asume la cultura como marco de referencia donde se producen las interacciones comunicativas, la construcción y narración de las identidades y los procesos de comprensión y autocomprensión de significados, sistematizando la criticidad de la vida cotidiana como vía de acceso a las zonas de articulación que se despliegan entre la apropiación/resignificación de las audiencias y la puesta en común de significados y producción de sentidos de los medios de comunicación.

Palabras clave: representaciones sociales, medios de comunicación, procesos de recepción.

\section{Process of reception and appropriation of the mass-media's discuss in the precarious settlement: Study of Case (Nueva Asunción, Hyndaya)}

\begin{abstract}
The present investigation is inscribed in the theoretic perspective of the Social Representation. From the practical reflection line deepens in the world of the daily life of the social human beings from a specific social sector and their interactions in the construction of the sense. Proposing it to investigate about the objective level and discursive aspect of the symbolic universes constituted in relation to the mass-media and their narrative/speeches in the molding of reality. The analysis of the representational structures as a socially thought constructed in a marginal community named Nueva Asunción (Hyndaya) it is based on the culture as a reference standard, where it is produce the communicative interactions, the construction and narration of the identities and the comprehension and the self- comprehension process of the meanings systematizing the critic of the daily life as a way of the access to the articulation zones that are generated betweens the appropriation/signification of the audiences and putting in common meanings and the production of the sense of the mass-media.
\end{abstract}

Keywords: social representations, media, reception processes.

\section{Referencia normalizada}

MASSÓ SOLER, Perla Dayana (2014): "Procesos de recepción y apropiación de discursos mediáticos en asentamientos precarios: Estudio de caso (Nueva Asunción, Hyndaya) ". Estudios sobre el Mensaje Periodístico. Vol. 20, Núm. 1 (enero-junio), págs.: 469-486. Madrid, Servicio de Publicaciones de la Universidad Complutense.

Sumario: 1. Introducción. 2. Sinfonía marginal para Tam-Tam y orquesta. Woï para dos koras y un balafón. 3. Variaciones sobre un tema metodológico. 4. Allegro de Sonata: Representaciones sociales y vida cotidiana. 5. Adagio Sostenutto por Hindaya. Llora el Tam-Tam. 6. La vida cotidiana en Nueva Asunción (Hindaya). 7. Los medios de comunicación masiva y sus relatos/discursos en la modelación de la realidad. Una aproximación a los procesos de recepción del discurso periodístico. 8. Conclusión. 9. Referencias bibliográficas. 
Nous savons que nous sommes beaux. Et laids aussi. Le tam-tam pleure et le tam-tam rit ${ }^{1}$. Manifeste des Étudiants Noirs de Paris (1922)

\section{Introducción}

El estudio sobre los procesos de recepción y apropiación de discursos mediáticos en Nueva Asunción, Hyndaya es una propuesta que se inscribe en una investigación esencialmente antropológica, que parte de la apropiación ilegal del suelo urbano (y sus impactos en la construcción de identidades comunitarias sumergidas) hacia la apropiación de producciones simbólicas. En este sentido partimos del estudio etnográfico de los más representativos y densamente poblados de estos asentamientos precarios, como es Hyndaya. En el caso específico del artículo que se presenta establecemos recortes en el abordaje de la realidad para indagar en la especial significación otorgada a los medios de comunicación masiva (componente del consumo cultural en estos espacios sociales) y la apropiación simbólica de sus relatos en la modelación de la realidad.

\section{Sinfonía marginal para Tam-Tam ${ }^{2}$ y orquesta. Woï ${ }^{3}$ para dos $\operatorname{koras}^{4}$ y un bala- fón ${ }^{5}$}

Las ciencias que parten del homo culturalis como objeto de estudio no encuentran su auténtica razón de ser sino cuando se desvanece el rostro familiar del otro para que aparezca la cara inquietante y fascinante del otro. La alteridad como construcción simbólica se conforma a partir de una relación social y en torno a la diferenciación de las colectividades humanas, brindando un espacio invaluable para el análisis de la diversidad, la pluralidad, la diferencia pero también del "Nosotros" como consolidación de identidades particulares y comunitarias.

Como señala el eminente antropólogo norteamericano Franz Boas (1911) es imposible explicar los tipos de cultura afirmando que son similares debido a la similitud de la mente humana. La hipótesis etnológica de una explicación de los comportamientos humanos por la pertenencia étnica confirma cada vez más la hipótesis sociológica de una conformación de los hábitos culturales a partir de la pertenencia social, entendiéndose, entonces, la variabilidad cultural como una propiedad distintiva de las colectividades humanas. La cultura forma modelos reconocibles y persistentes, y constituye el sistema significante a través del cual todo orden social se comunica, se reproduce, se experimenta y se investiga (Williams, 1981:13).

Desde esta perspectiva partimos de la cultura como marco de referencia donde se producen las interacciones comunicativas, la construcción y narración de las identidades (individual y colectiva), los procesos de comprensión y autocomprensión de significados, donde los sujetos aprehenden los contenidos significativos del discurso social y lo incorporan a su universo experiencial y subjetivo «en un proceso que al-

1 Sabemos que somos bellos. Y feos también. El tam-tam llora y el tam-tam ríe.

2 Tambor del África Occidental, inseparable del griot.

3 Poema cantado, oda

4 Arpa guitarra mandinga creada en el siglo XV por los griots de la región de Kabú, en Senegal, para acompañar los poemas épicos.

5 Marímbula bambará que acompaña la recitación de poemas épicos. 
gunas veces tiene lugar sin esfuerzo y otras supone un esfuerzo consciente» (Thompson, 1998:66)

Los medios masivos de comunicación devienen en este contexto escenarios de diálogo y discusión social, representadores de la realidad, instrumentos de legitimación y socialización de contenidos, generadores de conocimiento, referentes en el mundo cotidiano, a la vez que instituciones socializadoras con fuertes implicaciones en el ámbito cognitivo y socio-afectivo de los sujetos a partir de su capacidad para construir sentidos que re-producen y significan la realidad en tanto experiencia de construcción colectiva. «Son mucho más que sólo medios. Son lenguajes, metáforas, dispositivos tecnológicos, escenarios donde se genera, se gana o se pierde el poder; son mediaciones y mediadores» (Orozco, 1997) e influyen en una pluralidad de ámbitos o dimensiones del mundo de la vida: la realidad, la ideación, el mundo onírico, el hacer y el pensar, y los procesos simbólicos-culturales que generan son no sólo reflexivos sino constitutivos de la construcción de la realidad, y tan fundamentales como los procesos de índole económica o político-social.

Al mismo tiempo, se hace imprescindible pensar sus audiencias como sujetos culturales que participan en una pluralidad de espacios y submundos donde se construyen sus identidades y se le otorga sentido a sus prácticas y producciones materiales y simbólicas. La cuestión de las audiencias y los medios de comunicación remite a un proceso dialéctico, de reciprocidad e intercambio, donde el sujeto se modifica, y a su vez modifica aquello de lo que se apropia, re-orientándolo, re-constituyéndolo, resignificándolo. Lejos de las simplificaciones y automatismos que privilegian el contenido de los mensajes, la pregunta por los efectos debería dirigirse a pensar qué es esa gente para que haga lo que hace con los medios. [...] La pregunta: ¿qué es este receptor? nos instala en los confines de lo ontológico. (Schmucler, 1997:116). Schmucler enuncia una tesis para el desarrollo de la presente investigación, reconociendo la trascendencia del análisis particularizado del receptor, su marco cultural de referencia e historicidad en el abordaje de los usos y apropiación de los enunciados mediáticos.

Coincidimos con Moscovici en que «los estudiosos deberían mirar el mundo desde el punto de vista de las minorías y ya no exclusivamente desde el punto de vista de las mayorías de las masas unitarias, como lo han hecho hasta ahora» (Moscovici, 1980: 690). Por lo que nos proponemos indagar en el mundo de la vida cotidiana del asentamiento precario Nueva Asunción (Hyndaya) y el rol de los medios de comunicación masiva, con énfasis en el discurso periodístico, y su construcción de la realidad.

\section{Variaciones sobre un tema metodológico}

Nuestra propuesta metodológica articula una postura de carácter dialógico entre lo cualitativo y cuantitativo, y las preocupaciones de orden epistemológico que la sustentan remiten a la construcción de un conocimiento que asume como eje fundamental a quienes producen, reproducen y viven la realidad social. Partiendo del método etnográfico, que coloca el acento en la dimensión cultural de la realidad objeto de análisis, se reivindica la vida cotidiana como escenario primordial en la comprensión de la realidad socio-cultural y se reconoce la importancia de las formaciones subjetivas (creencias, mentalidades, mitos, prejuicios, estereotipos) y la intersubjetividad en 
la construcción del conocimiento humano. Sin dejar de ser un estudio esencialmente cualitativo, dado el énfasis en las prácticas culturales y construcciones simbólicas, y la asunción de una realidad epistémica que transcurre no sólo en los marcos de lo objetivo sino de lo subjetivo e intersubjetivo, se asume la complementariedad de lo cualitativo-cuantitativo como perspectiva metodológica para encarar el mundo empírico de Nueva Asunción (Hyndaya) y sus representaciones sociales.

Dicha complementariedad en el abordaje del fenómeno representacional convoca, así mismo, y legitima la utilización de diferentes instrumentos y métodos de análisis (Jodelet, 1986, Abric 2001, Ibáñez, 1994). La investigadora María Auxiliadora Banchs (2000:2-6) ha señalado al respecto que las propuestas podrían agruparse en dos dimensiones fundamentales: estructural y procesual, destacándose en la primera el uso del método experimental y análisis multivariables para identificar la estructura y organización de la representación, mientras el enfoque procesual constituye un abordaje hermenéutico, focalizado en los procesos cognitivos y de interacción social que inciden en la conformación de las representaciones y en la indagación de las producciones simbólicas, es decir, de los significados del lenguaje, a partir de los cuales los seres humanos construyen el mundo en que viven.

La Teoría-Metodología desarrollada por Grize (lógica natural del lenguaje), entiende la representación como un concepto semiótico y concibe el discurso como una actividad compleja donde se explicitan por excelencia las representaciones sociales. Se encuentra en una línea de continuidad con la "lógica operatoria" de Piaget al constituir una lógica de la verosimilitud, de carácter restringido y local en la medida en que alude directamente a la situación inmediata de los interlocutores. El eje central o neurálgico de esta perspectiva metodológica son las representaciones discursivas que se explicitan en las respuestas verbales de los sujetos, por lo que insiste en el diseño de instrumentos que permitan verbalizar actitudes, opiniones y creencias.

El estudio se inscribe en la dimensión procesual, se propone no sólo identificar los contenidos de las representaciones que sobre los medios de comunicación masiva y sus relatos-discursos (con énfasis en el discurso periodístico) circulan en un sector sociológico dado, sino, que enfatiza, además, en el proceso en que dichas representaciones son construidas y las prácticas sociales que le sirven de marco de referencia. Se parte para ello de la propuesta plurimetodológica de Jean-Blaise Grize ${ }^{6}$ que presenta una imbricación y sistematización de métodos y técnicas de la psicología social, la sociología y la lógica natural del lenguaje en el análisis tanto de la forma como del contenido de las representaciones sociales.

\section{Allegro de Sonata: Representaciones sociales y vida cotidiana}

Las representaciones sociales que se inscriben en el marco de una teoría referida al saber de sentido común que opera distinciones de lo cotidiano son una forma de conocimiento práctico socialmente elaborado, que se genera en la dinámica de la vida cotidiana y es compartida por los individuos de la colectividad. Pero no todo sistema de opiniones o

${ }^{6}$ Matemático y experto en lógica. Fundador del Centro de Investigaciones Semiológicas de Neuchâtel especializado en el estudio de la lógica natural. 
conocimiento práctico de la realidad constituye una representación social. Es imprescindible que los contenidos representacionales se estructuren en tres dimensiones interdependientes: información, actitud y campo de representación. La representación se constituye a partir de la cantidad y calidad de la información que se posea en torno al sujeto, aspecto de la realidad o fenómeno objeto de representación, conformando una orientación favorable o desfavorable hacia él (actitud). Los contenidos que constituyen el corpus de la representación social se jerarquizan y organizan en un núcleo figurativoproposiciones, significados e imágenes simbólicas que simplifican y esquematizan el objeto representado, explicitándolo-, y elementos periféricos que contienen las informaciones y valoraciones ya constituidas sobre el objeto de representación.

El reconocimiento de los marcos sociales en que se produce el fenómeno representacional nos conduce al abordaje de la vida cotidiana. Las representaciones sociales en su doble aspecto psíquico-relacional se explicitan o manifiestan en el complejo entramado de creencias, valores, actitudes, opiniones, normas y tradiciones que moviliza el individuo en sus interacciones sociales y que le permiten dar sentido y organizar su mundo de vida cotidiana.

El mundo de la vida cotidiana remite a una construcción intersubjetiva resultado de la interacción y articulación de los distintos ámbitos de la vida social, es aquel que se instaura en la conciencia de los individuos como una realidad objetivada, como la realidad por excelencia, y en él se construye colectivamente y de manera compartida la identidad de los sujetos sociales.

\section{Adagio Sostenutto por Hindaya. Llora el Tam-Tam}

Los asentamientos precarios o comunidades periféricas, a pesar de su centralidad en el análisis antropológico urbano, constituyen un sector sociológico de escasa visibilidad y se configuran como una zona ignota o inexplorada en los estudios de recepción en Cuba. Partiendo de la necesidad de articular/ integrar dentro del discurso que los medios vehiculan las realidades contextuales de minorías "marginadas" en el entramado social y comunicacional analizamos el mundo de vida cotidiana del asentamiento precario Nueva Asunción (Hyndaya) y los universos simbólicos constituidos en torno a los medios de comunicación masiva y sus relatos/discursos en la modelación de la realidad.

Una primera aproximación al sujeto que se investiga resulta del análisis toponímico. La toponimia constituye una herramienta indispensable en el análisis social, devela pautas de elevada sutileza, elucidando, en un ejercicio hermenéutico, las complejas interacciones e interdependencias que se producen entre el hombre y su medio; en un nombrar que es plasmación de características morfológicas, zoológicas, psicosociales, y que ineludiblemente es un nombrarse. Rafael López Valdés (1980) en sus investigaciones sobre los componentes africanos en la historia étnica de Cuba establece la diferenciación, a modo de convención semántica, entre dos términos de connotación conceptual distinta muy recurridos en las indagaciones etnográficas: etónimo (nombre que sirve para designar una comunidad, siendo de aceptación general y uso por sus integrantes para autodenominarse) y denominación étnica (nombre con que se conocen ciertas comunidades y que no fueron usados con fines de autodenominación.) 
Etónimos y denominaciones étnicas exhiben funcionalidad diversa en el contexto social. Nueva Asunción, podría decirse, es la denominación de la comunidad sujeto de estudio, y su funcionalidad remite a lo institucional-corporativo, a la observancia de los principios normativos y preceptúales de la organización social, en dos dimensiones: como obediencia y como estrategia de reconocimiento/integración. El extranjero sólo podrá llegar en su bregar hasta Nueva Asunción, la primera puerta, abalorio del halcón para enmascararse; a él, Hyndaya le será vedado. Hyndaya es un etónimo resultado de los procesos de apropiación y resignificación del discurso mediático, su eclosión coincide con la proyección en el espacio de aventuras de la televisión cubana del dramatizado El Halcón entre 1981 y 1982, y se ubica en un contexto de explosión demográfica de la comunidad. Escrito por el periodista y narrador Amado Cabezas, El Halcón cuenta en los roles protagónicos con Irela Bravo (Jachet) y Jorge Villazón (Memé) y constituye una recreación del mundo árabe, sus matrices culturales y complejas estructuras de poder y dominación. Hyndaya nos remite a la lucha por el derecho a la tierra, a la resistencia, valores intrínsecamente asociados al surgimiento y desarrollo de este asentamiento poblacional.

Ubicado en el Consejo Popular Flores de la ciudad de Santiago de Cuba, Hyndaya es un asentamiento informal de más de 1200 habitantes, resultado de la invasión de construcciones clandestinas, en un proceso que se inicia a finales de los 60 y alcanza su punto álgido en las décadas de 1980 y 1990. El asentamiento, de accesibilidad limitada y difícil visibilidad, se sitúa en una zona de riesgo (terreno cenagoso) y de degradación física en las inmediaciones de la ciudad. Al no ser incorporado al proceso de urbanización ostenta rasgos de lo que podría denominarse una nueva ruralidad-urbanidad, convergencia de formas de vida urbana y semirural (ausencia de calles pavimentadas, alumbrado público, servicio de alcantarillado, el $90 \%$ del fondo habitacional es de madera, zinc, cartón y otros materiales reciclables).

Se observa aquí una situación de pobreza, marcada por el deterioro de las condiciones de vida, la precariedad del espacio habitacional, la incapacidad para satisfacer necesidades básicas y mediatizada por el acceso a la educación y la salud, por lo que podemos hablar de pobreza con protección y garantías de servicios sociales.

\section{La vida cotidiana en Nueva Asunción (Hindaya)}

La vida cotidiana como plasmación/revelación de un mundo intrasubjetivo, que remite a la experiencia directa e íntimamente experimentada, y a la vez intersubjetivo, derivación de la compleja dinámica de interacciones y retroactuaciones con el otro, con los otros, constituye el marco de referencia desde el cual partimos en el abordaje de los procesos representacionales y universos simbólicos de Nueva Asunción. En la comprensión/exégesis de la realidad y sus dimensiones de sentido y en todo proceso de articulación de transformaciones sociales es imprescindible partir de la percepción/valoración de la realidad directamente experimentada y de los niveles de concientización/criticidad de los sujetos sociales ante la experiencia cotidiana. El estudio de lo cotidiano no sólo como objeto teórico o cuerpo conceptual sino, y fundamentalmente, como objeto y entidad actuante, nos acerca al conocimiento y elucidación de la intríngulis del comportamiento social. 
Desde una perspectiva vigostkiana ${ }^{7}$ lo meramente individual (en lo actitudinal, axiológico, de construcción de sentido) deviene consecuencia y resultado de lo social, sustentándose en los procesos de apropiación que realiza el individuo de todo el sistema relacional, de conocimientos y saberes en que se organiza y estructura la sociedad, lo que le permite construir y reproducir su propia realidad en la diversidad de ámbitos y dimensiones de la vida social.

La falta de visión concreta de la propia realidad ha llegado a convertirse a nivel psicológico en un fenómeno de acostumbramiento, de naturalización, reconocido como estado de familiaridad acrítica. Pero existe en la vida cotidiana la posibilidad de transformar dicha familiaridad en criticidad. Y en ese ejercicio de trascender la unidireccionalidad/acriticidad de la experiencia diaria se genera un espacio inigualable para el estudio y comprensión de la subjetividad social.

Ese espacio discursivo sobre la cotidianidad y sus implicaciones en la construcción de sentidos constituye el marco de referencia de la presente investigación, que lejos de establecer formulaciones conclusivas en torno a la estructura y contenido de la representación de la vida cotidiana se propone, esencialmente, el conocimiento de aquellas informaciones/valoraciones que configuran el núcleo central y de los elementos significativos que integrándose de modo particular en torno al núcleo dan cuenta de los constructos cognitivos/afectivos que lo conforman. Para ello se empleó, desde una perspectiva procedimental, instrumentos operatorios como el cuestionario, la entrevista en profundidad y una técnica proyectiva que nos permitió acceder a los universos semánticos construidos en torno al objeto de investigación.

El examen del material factual con el fin de extraer significado relevante del conjunto de informaciones compendiadas combina la frecuencia de aparición de los términos y el orden medio de evocación. Considerándose cogniciones centrales del núcleo figurativo aquellos términos evocados por un mayor número de sujetos y en orden preferencial. El contenido fue analizado posteriormente y triangulado con las informaciones obtenidas a través de la observación participante y la entrevista en profundidad, combinándose las interpretaciones de los datos cualitativos y cuantitativos.

En la indagación sobre el mundo de vida cotidiana de Nueva Asunción (Hindaya) la técnica proyectiva utilizada fue la Asociación Libre de Palabras, presentando la vida cotidiana o realidad vivida diariamente como término inductor. La técnica consistió en solicitar a los sujetos entrevistados las frases o significados asociables a su vida cotidiana. Además se incluyó en la encuesta una pregunta abierta consistente en la descripción mediante el completamiento de frases de la realidad vivida diariamente. En la entrevista se profundizó en el aspecto motivacional, condiciones de producción y reproducción social, sistemas de referencia, reflexiones personales y expectativas de vida.

${ }^{7}$ Lev Semionovich Vygotski (1896-1934) fundador y primer gran teórico del enfoque histórico social, revoluciona los fundamentos epistemológicos, teóricos y conceptuales de la psicología con el fin de crear una teoría y práctica psicológicas basadas en el Materialismo Dialéctico e Histórico, y capaz de explicar, comprender y transformar al hombre. Desde la perspectiva vygotskiana el hombre es resultado del contexto social en que vive, pero como sujeto autodeterminado y no como cosa producida. 
Los términos más evocados por los sujetos de Nueva Asunción (Hyndaya) en la descripción de su cotidianidad, independientemente de la edad o sexo, develan un fuerte componente afectivo/emocional de carga negativa:

$\begin{array}{cccc}\text { MISERIA } & \text { NECESIDAD } & \text { SUFRIMIENTO } & \text { LUCHAR LA VIDA } \\ \text { PASAR TRABAJO } & \text { SIN ESPERANZA } & \text { MONOTONÍA } & \text { DURA }\end{array}$

Las evocaciones enunciadas de menor carga negativa son:

UNIDAD NORMAL REGULAR IGUAL

La pormenorización en el análisis del material factual partiendo de las variables sociodemográficas explicita la heterogeneidad de significaciones que asume la vida cotidiana en dependencia a los distintos grupos sociales.

En los individuos de más de 50 años se presentan las evocaciones de menor carga negativa a la vez que es más acentuada la familiaridad acrítica. Las evocaciones refieren como elemento esencial la familia, la salud, la convivencia:

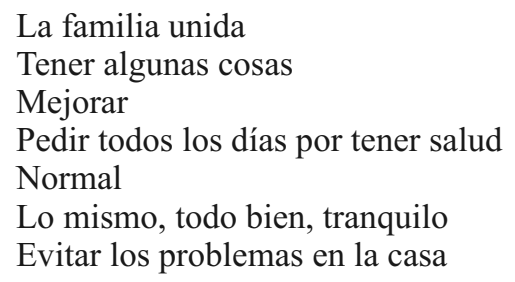

Para los estudiantes la vida cotidiana se presenta fundamentalmente asociada al estudio, al esfuerzo para alcanzar sus sueños, anhelos, expectativas laborales y de mejoramiento de vida:

Estudiar para ser alguien en un futuro

Luchar para el día de mañana tener una vida mejor

Esfuerzo, Sacrificio

Sueños

Cambiar esta vida

Obligación

Trabajar para ser alguien y tener lo que yo quisiera

Mucho estudio y de dedicación

En las mujeres amas de casa, la representación de la vida cotidiana se configura a partir de alusiones a la actividad doméstica, los problemas de alimentación, la carencia de recursos para la normal reproducción de la vida:

Insoportable, infernal, aburrimiento

Apretada, escasez, dura

Yo no quisiera pasar más lo que paso todos los días

Luchar para resolver algo

Buscar la comida

Cansancio 
Dentro del amplio repertorio de significados y elementos cognoscitivos asociados a la vida cotidiana, en los individuos entre 21 a 40 años, independientemente del sexo, las evocaciones críticas y de connotación negativa se erigen como centrales:

- La vida diaria de nosotros es el pensamiento, la necesidad, una recondena (Mujer de 25 años, vendedora ambulante)

- Lo mismo contra lo mismo, no hay nada (Ama de casa, 28 años)

- Sufrimiento y necesidad. Tristeza. Monótona (Mujer de 32 años, trabaja como auxiliar de limpieza en una escuela)

- Stress. Hambre y Miseria (Hombre, 21 años, ex-recluso)

- Luchar la vida en la calle e inventar para no morirme de hambre (Hombre, 38 años, vinculado a la economía informal)

- La vida cotidiana del cubano es una fantasía. La realidad que vivo es pésima y hay muchas cosas que no se pueden decir (Hombre, 40 años, con vínculo laboral en el sector estatal)

El análisis integral de los resultados revela que los elementos centrales del núcleo de la representación sobre la vida cotidiana se jerarquizan y estructuran a partir de una relación Dentro/Fuera de la comunidad donde confluyen términos de connotación positiva y negativa.

\section{Dentro de la Comunidad:}

Positivos: Apoyo, Unidad, Normal, Familiaridad, Igual Negativos: Aburrimiento, Miseria, Mal, Monotonía, Obstinación

\section{Fuera de la Comunidad}

Positivos: Otra vida, Mejoría, Trabajo

Negativos: Miedo, Riesgos, Luchar la vida en la calle, Abuso

He sentido tantas cosas que ya no siento nada (sic)

Concebir la vida cotidiana como ámbito de satisfacción de las necesidades particulares de sujetos concretos en un intercambio permanente con su medio, nos lleva al análisis de la actividad cardinal que permite la reproducción de la vida: el trabajo, recurso generador de otros recursos. Pichón Rivières sostiene al respecto en su teoría del vínculo que las necesidades son la base motivacional del comportamiento, que ellas surgen y se desarrollan del movimiento interno del organismo y de su relación e intercambio con el medio; las necesidades primariamente son carencias, ante las cuales el individuo se moviliza para convertirlas en su contrario: la gratificación.

En la indagación en torno al trabajo como elemento constitutivo de la vida cotidiana que permite el mantenimiento de la sociedad se solicitó a los entrevistados enunciar palabras o expresiones asociables a este término. Las evocaciones se toman según el orden y la frecuencia en que fueron emitidas: Luchar la vida, Inventar, Buscar di-

8 Médico y Psiquiatra suizo-argentino. La originalidad y trascendencia de su teoría se sustenta en la visión dialéctica y sistémica-interaccional en el funcionamiento de los sujetos y los grupos, y al reconocimiento de los vínculos y relación entre la dialéctica, la homeostasis y la cibernética. 
nero, Agotamiento, Obligación, Esfuerzo, Hacer algo para mejorar la vida, Riesgos, Buscar la comida de la casa, Stress, Sacrificio.

Dos elementos se perfilan como centrales y estructuradores del núcleo

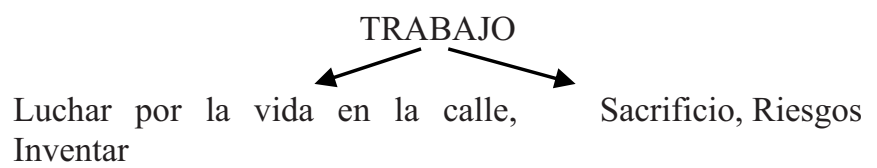

El primero se sustenta en el carácter informal de la actividad de producción y reproducción social propia de la comunidad y las estrategias personales de búsqueda del sustento para el hogar: ventas ambulantes, vinculación laboral transitoria, negocios ilícitos, asociada a la obtención de dinero, ganancia, medios de vida, en su doble dimensión económico-social, convirtiéndose en eje vertebrador de la representación. La calle deviene, entonces, no sólo en un espacio de transición donde se producen un conjunto de relaciones sociales específicas -superficiales y transitorias-, que se diferencia del espacio concreto del barrio o comunidad por la diversidad de normas y estructuras colectivas que rigen en ella en tanto espacio abierto, sino que es además escenario de intercambio, negociación y búsqueda de los medios necesarios para asegurar la subsistencia.

La segunda significación asociada al trabajo, de fuerte componente emocional/ experiencial, remite al esfuerzo que implica toda actividad laboral y específicamente la actividad económica informal, que se define por los riesgos, temor, inseguridad, tensión, transitoriedad, multas, detenciones, confiscación del producto, enfrentamientos con las fuerzas policiales, conflictos, fuga. Si partimos de que la población económicamente activa de la comunidad se constituye mayoritariamente de vendedores ambulantes (de maní, pasteles, frutas, hojuelas y otros productos) que operan en el centro del núcleo urbano, o se encuentra vinculada a otras tipologías de actividad informal y/o ilegal este elemento deviene medular en la representación.

En sentido general las prácticas ilegales son parte constitutiva de las estrategias de supervivencia desplegadas por los individuos de Nueva Asunción (Hindaya). Dada la amplia gama de necesidades insatisfechas, y no sólo de necesidades vitales o primarias, sino también de necesidades de consumo, de acceso a los medios de comunicación y a ciertos bienes y servicios fetichizados por la sociedad, la cuestión de la legalidad/ilegalidad queda relegada a un segundo plano, adquiriendo centralidad la satisfacción de las necesidades insatisfechas aún cuando ello implique la transgresión de normas establecidas por el orden jurídico positivo. El análisis de este ilegalismo generalizado desde la perspectiva del actor revela su racionalidad en las fuerzas motivacionales que sustentan dichos modos de actuación y estrategias de subsistencia: satisfacer las necesidades básicas y emergentes en un entramado de redes sociales que se encuentra por fuera de la circulación del mercado del trabajo. En esta red de vínculos se configura un tejido social marginal percibido por las normas sociales instituidas y el derecho positivo como violatorio. 


\section{Los medios de comunicación masiva y sus relatos/discursos en la modelación de la realidad. Una aproximación a los procesos de recepción del discurso pe- riodístico}

En el mundo de vida cotidiana, constituido por el conocimiento funcional de la realidad y las prácticas, rituales y procesos preceptúales y de apropiación cultural que en él se establecen, la institución de los medios de comunicación masiva se muestra íntimamente relacionada con los procesos de producción, reproducción y distribución del conocimiento.

Los contornos del espacio simbólico en el que vivimos se nos revelan, justamente, a través de los medios de comunicación masiva que permiten la integración y dan coherencia a los contenidos socialmente relevantes en alusiones significativas a las prácticas inherentes al mundo social. Los medios no son hegemónicos en la producción de posibilidades o alternativas de adquisición del conocimiento, pero si constituyen una plataforma de puesta en común de la experiencia y el conocimiento fragmentado, creando un terreno idóneo para la producción y reproducción del discurso social.

Entre la realidad, los medios de comunicación y los receptores se produce una relación dialéctica y de isometría donde la acción mediológica ostenta función mediadora frente al individuo y la realidad. Al decir de Denis McQuail los medios de comunicación masiva constituyen una plataforma o vehículo de información y opinión; un espejo, que refleja una imagen de la sociedad con respecto a sí misma, y con relativa distorsión, a la vez que un filtro, que selecciona partes de la experiencia para dedicarles una atención especial y descarta otros aspectos, ya sea o no deliberada y sistemáticamente.

La construcción social de la realidad, en tanto proceso subjetivo e intersubjetivo, se define como un espacio de interacción y retroacción entre los discursos mediáticos y la experiencia cotidiana, donde la experiencia cotidiana adquiere rol primario como concreción de ámbitos y acciones reales y posibles del ser y el existir. Pero a su vez el consumo de discursos mediáticos constituye un proceso significativo e inescindible del mundo de vida cotidiana, fundamentalmente en aquellos contextos de precariedad o vulnerabilidad social donde las condiciones materiales de existencia constriñen el consumo cultural a producciones massmediáticas, dado el limitado acceso a otras formas culturales de consumo.

El objeto que se examina es la representación subjetiva y compartida socialmente sobre la institución de los medios de comunicación masiva, con énfasis en el discurso periodístico, desde criterios relativos a la imagen de la realidad que modelan en los receptores, la satisfacción de expectativas y el reflejo/identificación de sujetos particulares con el discurso mediático.

La indagación parte de la dimensión informativa como elemento básico, que remite al proceso de organización/estructuración de los conocimientos que se poseen en torno al objeto desde una perspectiva cualitativa/cuantitativa. En la identificación de las dimensiones de actuación de los medios de mayor incidencia y motivaciones para el consumo se aplicó una encuesta exploratoria a 58 sujetos y se realizó un primer grupo focal relativo a la funcionalidad de los enunciados mediáticos en el contexto del mundo de vida cotidiana de la comunidad. 
El análisis de las características habitacionales y socioeconómicas de 85 hogares de Nueva Asunción reveló que el medio de comunicación masiva de mayor tenencia y/o disponibilidad es la radio, sin embargo, la televisión comporta los mayores niveles de consumo dadas las relaciones de compartimiento y colaboración que se producen entre la vecindad y que sustentan la institución de las viviendas que poseen el medio televisivo como espacios comunes y puntos de encuentro en determinados horarios. El sistema de distribución y venta de periódicos y otras publicaciones impresas no llega a esta comunidad ni a otras del consejo popular Flores por lo que el consumo de los medios impresos se muestra particularmente deprimido. El 91\% de los sujetos encuestados manifestó no leer nunca o raramente periódicos y/o revistas.

Al indagar en las motivaciones para el consumo de determinados espacios o producciones de los medios de comunicación masiva se pueden establecer dos dimensiones o ámbitos de las respuestas explicitadas: consumo de espacios fictivos y/o musicales y consumo de espacios noticiosos.

En relación a los espacios fictivos y/o musicales los criterios enunciados revelan como elemento motivacional la evasión de la realidad, el placer y la distensión de los conflictos cotidianos:

\section{Hedonismo-Distracción- Evasión}

Uno se siente bien

Yo escucho determinado programa porque me gusta

[...] son agradables pero necesitamos más programación

Uno se entretiene...

Para reirme un rato y despejar la mente

[...] Todo eso es fantasía pero bueno a veces a uno le hace falta eso

Yo veo determinadas cosas de la televisión para sentirme mejor

[...] olvidar esta vida que está muy dura

Uno desconecta de tanta miseria [...]

Está bueno porque no hay más nada

Las motivaciones para el consumo de espacios o materiales noticiosos podrían describirse desde la institucionalidad, actualidad y prominencia atribuida por los sujetos a esta tipología del discurso mediático:

Institucionalidad: (relativa al carácter serio, formal de las informaciones que se transmiten y asociada fundamentalmente a comunicados de orden meteorológico)

[...] Ahí dan informaciones oficiales del estado

Dicen de verdad como son las cosas de los temblores

Para estar al tanto de los ciclones, los temblores

Informarme de los temblores

Saber sobre cualquier tipo de informaciones oficiales del departamento técnico de orientación al pueblo

Cuando los ciclones salen de verdad los que saben de eso

Se dicen cosas serias del mundo que uno no sabe

Actualidad: (Posibilidad de conocer el suceso mientras ocurre, proximidad de la información al hecho) 
Uno conoce lo último que está pasando por ahí

Hay que estar informado de las cosas de actualidad

Cuando hay pelota uno puede oír el juego mientras está pasando

Las cosas importantes que ocurren la ponen rápido por la TV

Prominencia: (relevancia social de aquello que publican los medios de comunicación masiva)

Se informa cosas que uno debe conocer

Ellos nos mantienen informados de lo que sucede en el mundo, nacional e internacional

Salen las cosas bonitas que se hacen y que todo el mundo tiene que saberlo

Ponen informaciones importantes como descubrimientos científicos o cosas de la naturaleza

Informarme de actos o cosas grandes que se hacen en el país

Dicen cosas importantes y ponen a los dirigentes de la Revolución

En la totalidad de los entrevistados la concepción del hecho periodístico se configura a partir de esta noción de prominencia y la atribución de contenido relevante al discurso mediático como objeto construido y a los actores que construyen este discurso. Lo periodístico también se construye por procesos de metonimia y tropologización.

Con el objetivo de profundizar en la actitud u orientación hacia el objeto de representación social y establecer los contenidos representacionales de mayor centralidad y estructuras subjetivas que lo acompañan se suministró un cuestionario a 160 sujetos de la comunidad, seguido de un grupo de focal y la aplicación de una técnica proyectiva.

El 59\% de los sujetos encuestados manifestó identificarse o verse reflejado en alguna medida en los contenidos socializados por el discurso periodístico frente a un $41 \%$ que declara no verse proyectado en ellos. El $75 \%$ de los individuos pesquisados otorga en una escala de valores los mayores niveles de veracidad/legitimidad en el tratamiento de la realidad social a la radio, atribuyéndole a este medio valores específicos de proximidad y representación. En la explicitación de las expectativas satisfechas y/o insatisfechas más de la mitad de los entrevistados declara que el abordaje de la realidad social en los medios de comunicación satisface algunas o ninguna de sus expectativas y otro número importante manifiesta que la realidad que se modela en el discurso periodístico es la de algunos o la de la minoría de los cubanos.

Los términos evocados con mayor frecuencia en la asociación libre de palabras para la descripción/valoración de la imagen de la realidad que los medios modelan son:

Educativa

Importante

Patriótica

Y también 


\section{Censurada \\ Omisión \\ Reiteración \\ Superfvicial}

En la descripción/valoración de la realidad que modelan los medios de comunicación masiva percibimos 3 indicadores de diferenciación implícitos en las declaraciones de los sujetos entrevistados: credibilidad, prominencia, nivel de realidad, develando aspectos esenciales que configuran la apreciación y postura crítica de los receptores ante la agenda de los medios.

\section{Credibilidad}

Que no todo es como lo ponen porque hay cosas que hay que verlas para creerlas

La realidad que reflejan los medios de comunicación no está al 100\%

Alli todo es bonito y la vida no es así

[...] obvian la realidad, las verdades

[...] por qué no ponen la verdad, todo lo que estamos pasando

Hay mucha hipocresía y engaño

Muchas de esas cosas son mentira porque después no se ven

\section{Prominencia}

Hablan realmente de muchas cosas pero hay muchas cosas importantes que no la ponen

En el noticiero y en la mesa redonda hablan más de otros países que de nosotros

Los medios de comunicación hablan de todo lo que quieren hablar pero no de lo que de verdad es importante, de lo que pasa en realidad

Siempre hablan de lo mismo, no reflejan la realidad de esta vida, lo que está pasando

Lo que de verdad tienen que decir, no lo dicen nunca

[...] Hay cosas que suceden en la vida que me gustaría que pusieran en los medios de comunicación

\section{Nivel de realidad}

No lo ponen todo como deberían ponerlo en la Televisión

La realidad que presentan los medios es muy poca por no decir ninguna

Se tienen que trasmitir las noticias pero luego uno tiene que ver las cosas claras

Yo creo que debería ser más libre y poner todo lo que pasa para entender mejor algunas cosas

[...] siempre ponen lo mismo, pasan videos del centro pero la realidad de la vida, la miseria, la necesidad no la ponen.

La revelación de los elementos valorativos y perceptuales del público en relación a la agenda mediológica nos sitúa en la dimensión del análisis contextualizado y la indagación de los ejes temáticos y preocupaciones prominentes de los receptores para el establecimiento de correlaciones posibles. La explicitación de los contenidos preferenciales en el abordaje de la realidad como respuesta a la pregunta: De ser usted periodista o director de un espacio televisivo, radial o de la prensa plana qué elementos abordaría preferencialmente en sus trabajos arrojó los siguientes resultados: 


\begin{tabular}{|l|r|r|}
\hline Cuestiones & Personas & \% \\
\hline La realidad de la vida & 146 & 91 \\
\hline La verdad & 105 & 66 \\
\hline Problemas Sociales & 97 & 61 \\
\hline Criterios relativos a la política informativa & 21 & 13 \\
\hline Prefiero no responder & 12 & 8 \\
\hline
\end{tabular}

\section{La realidad de la vida}

La realidad de esta vida tan dura

Lo que pasa la gente todos los días para vivir

Todo lo que acontece sea malo o bueno

Abordaría cómo viven las personas en los barrios marginales

La miseria y necesidad que se está viviendo

(...) Filmaría todo lo que estamos pasando

Pondría la lucha diaria para sobrevivir...

Los aspectos que abordaría es como viven las personas actualmente

\section{La Verdad}

[...] Me gustaría tratar la verdad de cómo son las cosas en la sociedad actual

[...] El elemento que yo abordaría por el medio televisivo fuera la verdad

[...] uno de los principales es hace falta más libertad de expresiones para decir la verdad

Si yo fuera periodista me gustaría entrevistar a todo ciudadano cubano y escuchar sus opiniones e inquietudes, su verdad sin ningún problema

\section{Problemáticas Sociales}

Los problemas fundamentales del pueblo y sus necesidades sin esconder nada

Los problemas económicos

La realidad sobre la salud y la educación

Los problemas que se nos presentan, falta de productos de primera necesidad y otras cosas

Los problemas más profundos que ocurren y no se conocen en todo el país

El problema de la alimentación y el transporte

Lo laboral y la convivencia social

[...] La violencia que hay entre los jóvenes

Los problemas que pasan en los centros de trabajo

La corrupción y la mentira de algunos dirigentes

\section{Criterios relativos a la política informativa}

El que me manden a abordar porque no se puede decir todo lo que se desea ni piensa (...)

Abordaría las cosas que se puedan

Si fuera periodista no podría decir toda la realidad sólo algunas cosas

Hablaria de cuestiones que no me causen problemas

Tendría que hacer trabajos de política y esas cosas

La representación subjetiva que sobre los medios de comunicación construyen los sujetos de este sector sociológico se inscribe en la intersección entre el discurso social constructor de la realidad que los medios vehiculan y la construcción cotidiana y 
sistemática que realizan los sujetos sin pasar por los medios de la realidad social. El análisis de los procesos de apropiación y motivaciones para el consumo de enunciados mediáticos en la comunidad remite a contenidos cognitivos y axiológicos estrechamente relacionados con la autoimagen del sujeto y/o grupo social y el sistema funcional de referencias y nociones de lo real que constituye su vida cotidiana. Si bien las expectativas del público rebasan en su generalidad las posibilidades espacio-temporales y de cobertura temática que objetivamente pueden hacer los medios de comunicación masiva, se advierte de lo anteriormente expuesto la disociación/asimetría entre lo que es percibido y el sistema de expectaciones, la realidad directamente experimentada y la realidad modelada por la acción mediológica, las significaciones y sentidos que estructura la experiencia cotidiana y las autodescripciones que la sociedad realiza de sí misma a través de los medios de comunicación.

\section{Conclusión}

Indagar en la vida cotidiana como objeto de análisis y representación nos sitúa en el abordaje de la pluralización de la subjetividad social y la multiplicidad de referencias axiológicas que lo cotidiano esencializa. No todo objeto social puede constituirse en objeto de representación, es imprescindible su reproducción/estructuración en los discursos sociales: conversaciones cotidianas, enunciados mediáticos y un sistema integrado de valores que lo sustente. La experiencia cotidiana constituye en sí misma un objeto social privilegiado que alude a una pluralidad de objetos de representación- familia, religión, trabajo, identidad- constitutivos y fundantes de la vida cotidiana.

En el análisis de las estructuras representacionales, como pensamiento socialmente construido, la realidad contextual deviene punto de partida y elemento neurálgico que permite el acceso y comprensión de las interacciones sociales y los procesos de constitución de los universos simbólicos consensuados. Razón por la cual iniciamos este abordaje desde la criticidad de la vida cotidiana sustentada en la descripción/valoración de los propios sujetos de la comunidad de su experiencia diaria.

El lenguaje cotidiano en Nueva Asunción (Hindaya) registra y sistematiza el uso de expresiones y términos asociados a la vida diaria como plasmación de actitudes, posturas y realidades: luchar la vida, inventar, conseguir, riesgos, sacrificio, el pensamiento, resolver, bregar en la calle, estar en el fuego.

Se naturaliza la carencia, resignación, fatalismo y lucha constante por la vida como consustanciales a lo cotidiano, así como se aprecia una fuerte orientación en el presente y relativa poca capacidad en la planeación del futuro, elemento que condiciona un sistema de aspiraciones y expectativas tendientes a la satisfacción de necesidades básicas e inmediatas.

La construcción de significados, selección de informaciones y demandas sociales de esta colectividad se sustenta en una realidad contextual que remite a procesos de condensación y adaptabilidad de la conducta al ambiente y da cuenta de la evaluación emocional y subjetiva que realiza un sujeto concreto de sus condiciones objetivas de existencia y las posibilidades de satisfacer necesidades ineludibles para la reproducción de la vida dentro de un marco social establecido. 
Los actos y procesos de recepción de producciones mediáticas ocupan un espacio significativo en el contexto del mundo de vida cotidiana de Nueva Asunción (Hindaya) articulándose de modo sistemático a los procesos más generales y complejos de construcción social de la realidad.

En la explicitación de valoraciones/percepciones sobre los medios de comunicación y en especial sobre el discurso periodístico, subyace un constructo cognitivo/afectivo asociado a la imagen de la realidad que los medios modelan. Este proceso de simbolización parte de matrices culturales que se generan en los entramados de la vida material y tangible del sujeto. De manera que la recepción y consumo de los discursos mediáticos está directamente condicionada por las características de la cotidianidad de los sujetos y sus condiciones habituales de existencia, generando un espacio en el que se producen diversas negociaciones, resignificaciones y arreglos de lectura.

Las principales motivaciones para el consumo de enunciados mediáticos se estructuran a partir de la concepción de los medios de comunicación masiva como entidades socialmente reconocidas e instituciones socializadoras que legitiman y construyen sentidos relativamente relevantes para la organización social. Los modos de apropiación de dichos discursos se presentan mediados por los contextos que involucran y modelan la experiencia cotidiana y los saberes funcionales de sentido común construidos en torno a los medios de comunicación y sus producciones.

En este sistema de motivaciones para la recepción subyacen de manera consustanciada necesidades de índole objetiva y subjetiva que condicionan la satisfacción de las expectativas generadas sobre dichos discursos:

- Necesidad de información

- Necesidad de integración, ser parte del todo que constituye la sociedad a través de la información compartida

- Necesidad de distracción/relajación

- Necesidad de conocimiento-vicarial-de otras realidades, es decir, edificación de la realidad indirectamente experimentada

- Necesidad de visibilidad social

La representación intersubjetiva y escalas axiológicas asociadas a los medios de comunicación como constructores de nociones de la realidad se sustentan en criterios de funcionalidad atribuidos por los públicos al discurso periodístico. La objetivación mensurable que remite a presupuestos de legitimidad/credibilidad de dicho discurso es consustancial a los procesos de simetría/asimetría, asociación/disociación que se producen entre la realidad directamente experimentada o vida cotidiana y lo que se modela como real por la acción mediológica.

Pensar los medios de comunicación masiva como un espejo que proyecta una imagen de la sociedad con respecto a sí misma, en forma de autodescripciones de lo real, supone ineludiblemente la comprensión de que las aberraciones en esa construcción/representación de la realidad producirán lecturas potencialmente críticas en sujetos, grupos y contextos sociales de escasa visibilidad, privados de ese ejercicio de la memoria en que la sociedad a través de los medios de comunicación se construye. 


\section{Referencias bibliográficas}

BERGER, Peter L. y LUCKMANN, Thomas (1968): La construcción social de la realidad. Buenos Aires, Amorrortu.

BLUMER, Herbert (1982): El Interaccionismo Simbólico. Perspectiva y método. Barcelona, Hora

COMBESSIE, Jean Claude (2003): La méthode en sociologie. Paris, La Découverture.

CONESA, Mercé (2000): Exclusió, pobresa i sense sostre. Barcelona, Diputació de Barcelona.

CORCUFF, Philippe (2003): Las nuevas sociologías. La Habana, Editorial Félix Varela.

FONSECA, Rafael (2002): El consumo de comunicados periodísticos en la región oriental de Cuba. Santiago de Cuba, Universidad de Oriente. Material en PDF.

GARCÍA CANCLINI, Néstor (1989): "Culturas híbridas. El espacio como problema multidisciplinario". Telos, vol. 19. Madrid, pp. 13-20

GARCÍA CANCLINI, Néstor (1992): "Los estudios sobre la comunicación y consumo: el trabajo interdisciplinario en tiempos neoconservadores". Diálogos de la comunicación, vol. 32. Lima, FELACS, pp 8-12.

GIACOMO, Jean Pierre (1986): “Alliance et rejets intergroupes au sein d'un mouvement de revendication". En DOISE, Willem y PALMONARI, Augusto (Eds): L'Étude des Représentations Sociales. Paris, Delachaux \& Niestlé.

GIANNINI, Humberto (199): La reflexión cotidiana. Hacia una arqueología de la experiencia. Santiago de Chile, Editorial Universitaria.

IBÁÑEZ, Tomás (1988): Ideologías de la vida cotidiana. Psicología de las representaciones sociales. Barcelona, Sendai.

IBÁÑEZ, Tomás (1994): Representaciones sociales, teoría y método. Psicología social construccionista. México, Universidad de Guadalajara.

JODELET, Denise (1986): "La representación social: fenómenos, concepto y teoría". En: MOSCOVICI, Serge (comp.): Psicología Social II. Pensamiento y vida social. Psicología social y problemas sociales. Barcelona, Paidós.

MCQUAIL, Denis y WINDAHL, Sven (1984): Modelos para el estudio de la comunicación colectiva. Pamplona, Eunsa.

MOSCOVICI, Serge (1961): La psychanalyse, son image et son public. Paris, PUF.

SCHMUCLER, Héctor (1997): Sobre los efectos de la comunicación en Memoria de la comunicación. Buenos Aires, Biblos.

SCHUTZ, Alfred (1974): El problema de la realidad social. Buenos Aires, Amorrortu.

THOMPSON, John (1998): Los media y la modernidad. Una teoría de los medios de comunicación. Barcelona, Paidós. 